\title{
TEACHER'S ROLE AND REPRODUCIBILITY OF DIDACTICAL SITUATIONS
}

\begin{abstract}
Gibert Arsac $^{1}$, Nicolas Balacheff ${ }^{2}$, Michel Mante ${ }^{3}$
Authors tapuscrit of: Arsac G., Balacheff N., Mante M. (1992) Teacher's role and reproducibility of didactical situations. Educational Studies in Mathematics 23 (5) 5-29.

Abstract: Is it possible to specify teaching situations and to control their effects on students' learning? This general question is essential regarding the scientific character of research on mathematics education. It especially concerns the teacher's role in the class: can she ensure sufficient fidelity to a predefined scenario? This question is of special importance in the case of an experimental scenario the design of which is the result of collaboration between a researcher and a teacher. This is considered here in the context of two case-studies. These case-studies exhibit two types of factors which tend to hamper fidelity in reproducing a given scenario:

- first, constraints on the teacher resulting from the didactical system: time constraints, success of the teaching process;

- second, teachers' conceptions about mathematics and learning. These results are considered with reference to prior research on didactical transposition and teacher's beliefs.
\end{abstract}

\section{INTRODUCTION}

\subsection{Formulation of the Problem}

The problem of reproducibility of didactical situations is a fundamental one insofar as we want to give a scientific status to the studies which deal with them. What kind of phenomena can we expect to reproduce when the same class situation is implemented by two different teachers in two different classes? That is obviously linked to the problem of the communication of the scenario of a didactical situation to a teacher, and thus to the description of this scenario.

Regarding our didactical problématique, our main concern in this paper is to clarify a theoretical framework which could allow us to describe and evaluate students' learning outcomes, that is, the kind of mathematical meanings they construct as a result of their activities during the class session. This raises the question of the teacher's role. Teachers make decisions and choices, which can have important consequences on students' learning. We shall try to describe the choices made by teachers and their effect on students' learning, and we shall look for the origin of these choices in both teachers'

${ }^{1}$ Laboratoire LIRDIS, Université Claude Bernard, Lyon, France

2 Laboratoire IRPEACS, CNRS, Écully, France

3 IREM de Lyon, Université Claude Bernard, Lyon, France 
personal beliefs about teaching and learning and the constraints of Mathematics Education as an institutionalized system.

This problem appeared to us in the context of research about the teaching and learning of mathematical proof and mathematical reasoning, the objective being to pass onto the children the responsibility of solving the problem and of deciding upon the correctness of their own solutions. We call this the devolution of the problem (Brousseau, 1986, p. 53). For the purpose of our experiments, we had designed a didactical scenario, including a precise description of the teacher's role. However, differences between the teacher's behaviour as observed in the classroom and that in the planned scenario appeared. Moreover, these differences appeared to us to be so important and such obvious obstacles to our initial research goals, that we thought that they were by themselves interesting and central phenomena. These phenomena are described and analysed in the first case study reported below. This case study shows that the teacher's behaviour is influenced by two specific constraints: time management and what we called her "epistemological responsibility".

In this initial study, the teacher was a member of the research team and she participated in all theoretical analyses and debates preceding the experiments. We wanted her to share and understand the ideas underlying the design of the scenario. Then, in order to study more deeply the problem of describing and communicating the scenario of class sessions, we designed a second experiment in which the teacher was not a member of the team. Not surprisingly, despite a thorough exchange with her before the experiment, the differences were more important in this second case than in the first one. It appeared then that to explain the teacher's behaviour it was necessary to take into account not only the constraints identified in the initial case study but also the teacher's ideas about teaching and learning.

\subsection{TheORETICAL FRAMEWORK OF THE EXPERIMENT}

We will often talk of class situations, so it is necessary to say briefly what we mean by this expression:

- We call content of the situation the specific content to be learned by students as a result of their participation in this situation.

- We call scenario of the situation the detailed description of the teacher's role and students' roles, time allowed for each activity, material details, social organization of the class and so on.

Naturally the satisfactory functioning of the class situation requires that links, interactions, and compatibility between content and scenario have been carefully considered. 
In this paper we will consider class situations with the following general characteristics:

- Children involved are 13 to 14 years old. They work in groups of four.

- The content of the situation is the learning of mathematical proof. Therefore scenarios are designed in such a way that the responsibility for the search of the problem's solution and for the decision about its validity are entirely left to students during a certain period of time. Later on, the teacher concludes and summarizes the 'lessons' of the activity.

Insofar as learning proof is concerned, the idea of transferring responsibility to students is a classical one $e^{4} .1$ It makes the content of the debate very important since that is where the question of proof is expected to appear. This implies that the problem must be chosen primarily for the quality of the debate it is likely to involve. Particularly it must lead to several different solutions (correct or not).

The basic hypothesis about learning underlying our approach is a constructivist hypothesis, which means that we consider that the learner constructs her knowledge by interaction with various situations. Thus, we will focus mainly on the question of the nature of the activity of the learner, insofar as we see it as the key to the construction of meaning. The general framework for the design of our situations is taken from Brousseau's theory of didactical situations (Brousseau, 1986) ${ }^{5}$. Yet it is important to note a striking difference between these situations and ours that we shall explain now.

Let us consider, for instance, Brousseau's classical problem of enlarging a jigsaw (Brousseau, 1981, pp 69-73):

The students work in groups of four or five and each group holds a specimen of a given jigsaw (Fig. 1). The problem is to enlarge the jigsaw in such a way that a length of $4 \mathrm{~cm}$ in the initial jigsaw becomes a length of $7 \mathrm{~cm}$ in the new one. Each child has to enlarge one or two pieces. In this case, false solutions (generally consisting of enlarging each side of the pieces by adding, instead of multiplying by, the same number) are normally refuted when students see that they cannot rebuild the jigsaw.

So, there exists a milieu which allows a "natural" selection of good solutions, a selection which does not depend essentially on teacher's decisions (Brousseau, 1989). This is the fundamental reason why, in this situation, the teacher can grant much autonomy to students. They cannot uncritically accept false solutions. But in other situations, the milieu is free of strong physical constraints. Instead it has mainly social constraints such as the necessity for students to come to an agreement about a common solution. The functioning of such situations and their

\footnotetext{
4 Cf. Arsac et al., 1988, Balacheff, 1987, Brousseau, 1975, Chazan, 1989, pp. 223-234, Lampert, 1988, Legrand, 1988, and Schoenfeld, 1988.

5 The main outlines of Brousseau's theory of didactical situations are presented in Brousseau 1986a, Brousseau, 1986b, and Balacheff, 1990.
} 
possible outcomes are not so well defined. The teacher cannot be so confident with them and can only wait and see. We will consider and discuss this last type of situation, considering the question of the teacher's role and its consequences on student's learning.

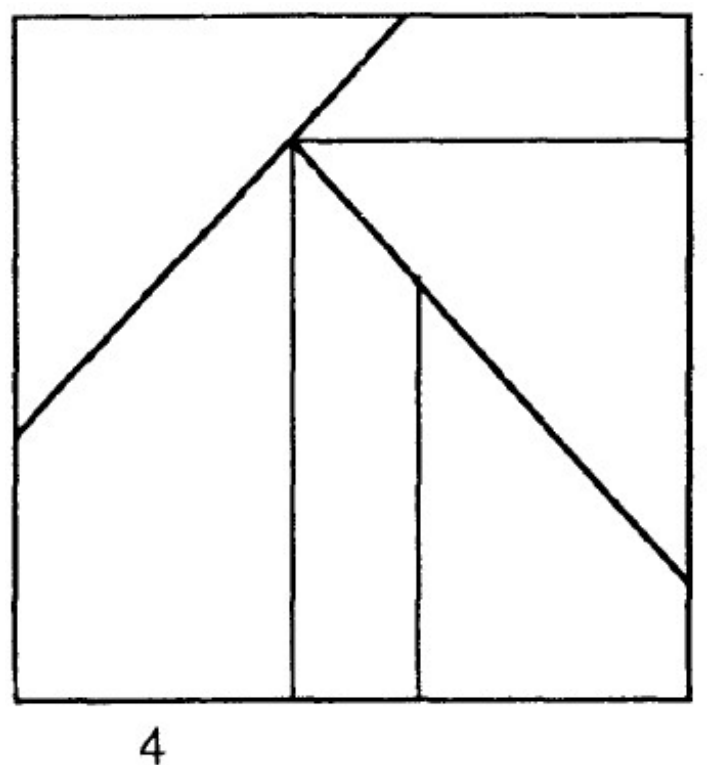

Fig. 1.

Of course, in the study of Brousseau's classical didactical situations, the problem of the organization of the situation, and chiefly of the milieu, is a central one. The analysis focuses on relations between students and the situation, rather than on the teacher's role (Margolinas, 1989, pp. 45-54). On the other hand, research on problem solving focuses on the relations between the student and the problem. This explains why there are not so many publications on the interactions between student learning and teacher's interventions, especially concerning the kind of situations we study here. Nevertheless, research on teacher's beliefs and their relationship to teacher's behaviour during class sessions indicates that this interaction certainly plays an important role (Cooney, 1988; Ernest, 1988).

\subsection{Methodology}

\subsubsection{General SCHEME of the Experimental Situations}

For the purpose of our research we designed several teaching experiments, with different settings. All of them shared the same general framework. 
Briefly, scenarios have two main phases:

- During a first phase, called the research period, the students' task is to solve a given problem and to write their solutions on a poster. The problem is chosen in such a way that several solutions can be reason- ably expected within the time allocated to a session (one hour or one hour and a half). The fundamental requirement for the teacher is that she must not interfere at a mathematical level. For example, she must not give indications to students about the validity of their tentative productions. Insofar as we want students to accept that they are in charge of their own work, it is necessary that the aim of producing a solution to be discussed appears by itself sufficient to motivate their activity. In some cases, we allowed the teacher to intervene at different levels (e.g. organization, etc.) and in others we allowed no interventions at all. We shall explain why later on.

- During the second phase, called the debate period, aiming at a collective discussion about the proposed solutions, the organization is the following: Students' solutions are written on a large sheet of paper and are then displayed as posters on the wall of the classroom. Each team has to analyze the posters and their spokes-person tells the class their criticism and suggestions. The criticism must be accepted by the team whose poster is discussed. Since the students involved are 13 to 14 years old, it is not possible to leave them free of any regulation. The management of the activity is then left to the teacher. Therefore, teachers' interventions are needed here for what we can consider as 'technical reasons'. But, more than that, it will be the responsibility of the teacher to institutionalize the debate's outcome at the very end. Thus, students as well as the teacher must have been witnesses of the phenomena to appear during this debate period. The social situation, as a whole, constitutes here the didactical milieu of the students' mathematical activity. But such a milieu is not sufficient by itself to guarantee the quality of the debate. We can then foresee that the teacher will have to play a role especially when the student group might come to an incorrect agreement or to an impasse.

The limits of the teacher's neutrality as a priori stated or as viewed by herself are at the core of our study. In addition, we wish to know how we can possibly organize teachers' interventions while preserving the mathematical meaning of students' activities.

\subsubsection{Methodology for Data Gathering}

In the case of the first experiment, we had an observer for each of the six groups of students and another one for the whole class. The session was video-recorded and the debates in each group were tape-recorded. Our analysis is entirely based on the transcripts of the records and on the remarks, observers made during the experiment. 
In the case of the second experiment, we first organized, before the sessions, three meetings with the teacher. These meetings aimed at explaining carefully to her the scenario of the didactical situation and the theoretical ideas underlying it. We even chose a teacher whose ideas about mathematical learning and about the role of children in the class appeared to be close to ours. The session was entirely tape-recorded and we have the full transcription of the discussions in two groups of students who were tape-recorded and of class discussion, the latter including all teacher interventions. Finally, we interviewed the teacher after she had listened to the tape and at the point where we had identified gaps between the scenario and implementation we asked her whether she saw any differences from her own point of view. When she answered positively, we asked her whether she was aware of these gaps and if she could explain them. This analysis has been made for the debate period since the teacher did not intervene during the research period.

This method, including careful description of the scenario, observations, and recording of the session, and finally interview of the teacher, is similar to that of Thompson (1984). Some differences lay in the fact that we did not observe the current activity of the teacher but her reactions to a perturbation. As the observation of a student faced with a problem allows us to infer her conceptions from her actions, the observation of the teacher and especially of the deviations from the planned scenario allows us to infer her conceptions. These inferences are controlled by a subsequent interview.

\section{TWO CASE STUDIES}

\subsection{The Truncated TRiAngle ${ }^{6}$}

The mathematical problem we chose for the first experiment was the following:

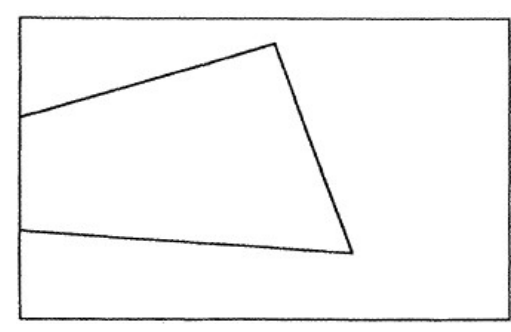

Fig.2

Write for other students a message allowing them to come to know the perimeter of any triangle a piece of which is missing. To do so, your colleagues will have at disposal only the paper on which is drawn a triangle and the same instruments as you have (rulers, etc.)

\footnotetext{
6 A complete report in French is available in Balacheff, 1988, pp. 465-562, for a more detailed presentation in English see Balacheff, 1991.
} 
Together with this text, a triangle as shown (Fig. 2) was given to students. All the teams in the classroom had the same materials.

A study we had made before this experiment led us to think that all the students would be able to enter the problem-solving process though with quite different solutions. We knew that some students, and thus some teams, would miss the fact the solution should fit the general case and not only the triangle given as an example. But we were sure that this would be pointed out during the debate, and then it would be taken into account, even with more strength than if the teacher had warned about it a priori.

The role of the teacher was to present the situation, and not to intervene in any case until all the teams had proposed a solution. Then her position was to regulate the debate and to allow each team's spokes-person to take the floor. The end of the sequence would come from a general agreement on the fact that one of the solutions, or a new one obtained as a result of the interactions, was accepted. In case of an agreement of the class on a false solution, the teacher was allowed to propose a new triangle to the teams, referring to the fact that such a triangle might be considered by the recipients. (Such material had been prepared taking into account what we learned from the first study). On the other hand, if more than one message was acceptable with no clear decision from the class, then the teacher was supposed to organize a vote to make the choice, asking the students to state their reasons for it. These teacher's interventions were supposed to allow a good regulation of the situation without depriving students of their mathematical responsibility.

\subsubsection{From "Light" INTERVENTIONS to "No" INTERVENTIONS}

The first experiment was carried out with students from the eighth grade (13 to 14 years old). The teacher was a member of the research team, so that the project was well known to her. The observations lasted two sessions of one and a half hour each. After the first session we were pleased with what had happened. Only after the second session did feelings of some difficulties arise. Beyond these feelings, the close analysis of the data gathered led us to discover the existence of phenomena which played a critical role in the teacher decisions, and thus in the students' behaviour.

The teacher's interventions, even if they seemed "light", tended to oppose the devolution of the problem. In particular, in order to guarantee that the research period would not be too long, she invited students to propose a solution as soon as she thought that what they had obtained was sufficiently developed, but with no information about the real feelings of these students. Also, some of the teacher's interventions were directed to calling students' attention to the word "any" (in the sentence "any triangle"). Doing so, she did not think that it was a mathematical intervention, insofar as she thought that it was merely due to the students' lack of careful analysis. But all these 
interventions led students to a feeling of dependence and the idea of a possible responsibility of the teacher for the validity of their answers.

A significant phenomenon is that the teacher (as well as the observers) did not realize what a continuous contact she kept with the students, making about one intervention every minute over an 80-minute period. The content of these interventions could have been trivial, as: "Are you O.K.?", or more important such as: "Are you sure you have carefully read the statement of the task?" Altogether we have counted, within these interventions, 129 different items. We see this phenomenon as an indicator of the intensity of the relationships between the teacher and her students in a situation we thought to be quasi-isolated from the teacher before we did a close analysis of the records.

The same constraints were an obstacle to the functioning of the second phase. After a first exchange of criticism by the teams' representatives, the teacher intervened because she thought that nothing positive would come out of the engagement with the problem -at least within the time available. The teacher then tried to facilitate the progress of discovery of a solution, calling explicitly for ideas and suggesting to start from these ideas to go further. Actually, it was quite clear from her attitude that not all these ideas were equivalent for her. For example, at one point, the teacher intervened with: "People have told me that perpendicular bisectors seem interesting, so try to work more on perpendicular bisectors... so using perpendicular bisectors, try to solve the problem stated... We will rewrite a message, if you want to do again the work you did yesterday... but not starting off quite like yesterday, because you've already brought out some ideas. OK, we're going to try to share the work. Well... There are three ideas... ".

The students' behaviour was deeply transformed by these interventions. Students got confused and they were no longer committed to any real discovery of a solution.

The teacher thought that she had kept the spirit of the sequence, the basic frame being: search for a solution and present criticism, new ideas and suggestions to go ahead. But only the superficial aspects of the intended sequence were still there. Its meaning for the students was fundamentally changed. They did not enter a true mathematical activity, as expected, but just a new school game not so different, except for the new and exciting social setting, from the ordinary situation. As the teacher acknowledged (off the record): "Now they are not searching any more, they're ready to accept just about any message... although they had arguments against... they didn't bring them out".

Following this first experiment we decided to organize a new one, within the same general characteristics, but in order to overcome the obstacles we faced during this first one, we chose the following modifications: 
- To remove time constraints, which means that we decided to leave open the decision on when the session finished. We thought that three or four sequences of about an hour each would be sufficient.

- To ask the teacher not to intervene, as strictly as possible, during the research period, and then to act only as a chairperson and as the collective memory ${ }^{7}$ of the class during the debate period.

Indeed, the teacher did not intervene at all, leaving students free to decide if they had a solution to propose. Four teams among the five reached a solution. The fifth one which was clearly close to giving up, finally proposed a "contribution" to the collective effort, as a response to the teacher's demand.

The data gathered show that students entered a discussion with some mathematical content in it, but which mainly consisted of an exchange of arguments pro and con not necessarily connected with one another. They argued about the different proposed solutions, but they did not prove them mathematically (Balacheff, 1991). The context of communication has really been taken into account as such by students, as their remarks on the proposed messages show. The main criticisms are related to the fact that this message must be understandable and usable by its recipients. But the problem of the validity of the proposed solution is not really considered. ${ }^{8}$ The involvement of some of the teams in the game, that is the fact that they were eager to win, had favoured the appearance of polemics: The strongest opponents to the "too complex" message were the authors of the "too simple", and conversely. Finally, after one solution was accepted as the solution by the class, the teacher asked students whether they were sure of that solution. They answered: "Yes because we have done it in a lot of cases." So, it is not sufficient to directly address the question of validity. In fact, when later on the teacher asked students about a possible mathematical proof of their solution, they gave one, showing that technically it was within their capability.

\subsubsection{Two Constraints: TIME AND EPISTEMOlOgy}

\subsubsection{THE TIME MANAGEMENT EFFECT.}

One of the essential constraints upon the situations observed is time. It is necessary to "open the time" in order to obtain the devolution of the responsibility to students. All explicit and a priori decisions concerning the timing of the situation are likely to be

\footnotetext{
7 To be the "memory" of the class means to take a record of what is said, in particular by writing students' decisions on the blackboard.

8 Referring to Brousseau's theory of didactical situations, we can say that the situation did not become a situation for validation (Brousseau, 1986, pp. 93-112).
} 
understood by students as an indication about the kind of knowledge to be used. Indeed, if the teacher tells students that they have little time to find a solution, it implies to them that this solution consists of a mere "application" of recent knowledge. But, in any case, the teacher has to ensure that the whole process will fit the limits imposed by the general school time- table. Thus, the teacher might have to modify the initial problem situation in order to keep all the activity within acceptable time limits.

Teacher's decisions for coping with these constraints tend to oppose the devolution of the problem situation to students. For example, before her intervention, it happened that students disagreed with some solution discussed in the group, but that they changed their minds after her intervention because of her positive reaction (Arsac et al., 1988). Actually, the teacher's interventions to call students' attention to the constraints of the problem reinforced their feeling of dependence related to a possible teacher evaluation of their production. As a matter of fact, they had no longer any real reasons to enter a "genuine" proving process, in a mathematical sense.

\subsubsection{EFFECT OF THE TEACHER'S EPISTEMOLOGICAL RESPONSIBILITY.}

The teacher feels the need of an acceptable closure. There was a huge tension between this need and the desire not to break the contract of "nonintervention". This tension is the indication of what we would like to call the teacher's epistemological responsibility (Balacheff, 1988, pp. 525-527).

In the context of our research, in order to make clear that mathematical proof is an efficient tool to establish the validity of a solution, it is necessary to obtain from the students the recognition that they are responsible for their production. The necessity of this devolution of the problem to students is not refuted by the observations we have made. On the contrary, these observations show clearly that to "give" a problem to students is not sufficient to guarantee they will feel they are in charge of its solution. The situation must be organized in such a way that it appears legitimate that the teacher does not take part in the decision. But this position of the teacher conflicts with her feeling of an epistemological responsibility which she keeps whatever the "contract" negotiated with the students may have been in order to obtain the devolution. She always feels that she is accountable for the mathematical meaning of her students' behaviour. Thus, sooner or later she must intervene to address the errors, or to obtain the production of acceptable mathematical solutions to the proposed problem. At the end of the second experiment, this responsibility leads the teacher to ask explicitly for a mathematical proof. It was not specified by the experiment scenario, nor considered as necessary in the eyes of the students. This demand was necessary for the teacher to allow her to come to an acceptable conclusion with respect to her responsibility as a mathematics teacher. 
The two constraints, time and epistemological responsibility, together constitute an obstacle to the good functioning of the debate period. After the students' criticisms, the teacher cannot leave the debate open because she does not foresee a possible positive conclusion, at least within the time space available for the experiment. As we specified it, the students' debate was supposed to lead to either the acceptance of a solution (probably after the modification of the initial one), or to set elements for the search of a new solution valid for any triangle. In one of the experiments, the teacher tried to bypass this process as she considered it was too uncertain. She asked students to propose "ideas" to continue beyond the initial proposals. To some extent, she thought that she preserved the story as a sequence of specific events: first proposal of solutions, critique and suggestions for new directions. But the meaning of students behaviours was deeply trans-formed. We can recognize here one of the phenomena identified by Brousseau (1986a, p. 289) which he calls, "Topaze effect". Brousseau emphasizes that this phenomenon comes from the management by the teacher of her uncertainty about possible students' productions at the end of the class.

\subsection{LINES Which INTERSECt OUTSIDE THE PAGE ${ }^{9}$}

The mathematical problem we chose for the second experiment was the following:

Two lines $D$ and $D^{\prime}$ intersect outside of a page. Write a method allowing anybody to draw the line containing point $M$ and the common point of the two lines $D$ and $D^{\prime}$, without going out of the page.

Together with this text the following figure was given to the students (Fig. 3).

We gave the teacher more precise indications than the second experiment of the first problem, since our aim was also to observe her behaviour carefully. The teacher had to remain at her desk during the research period.

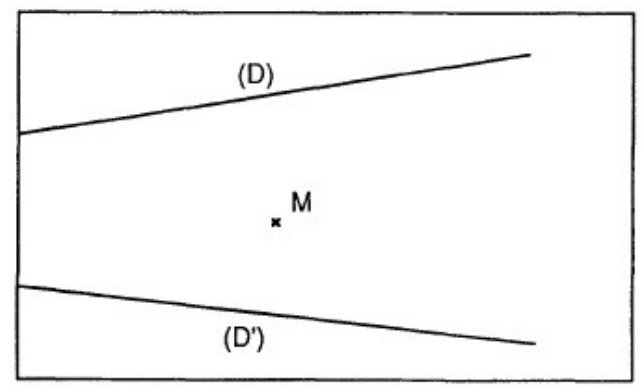

Fig. 3.

9 For a complete report in French see Mante, 1987. 
During the debate period the organization was the following: The posters were successively displayed on the wall of the classroom, in an order decided at a time between the two sessions devoted to the experiment (there were two sessions, one for each period). The choice of this order aimed at obtaining the best quality for the debate according to the analysis of the teacher and the researchers. The students had time to read and understand the posters and then to decide if they agreed or disagreed with the proposed solutions. This opinion was written on paper in each group in one of the two following forms:

- $\quad$ "We agree with this poster because..."

- $\quad$ "We do not agree with this poster because..."

This opinion was read by a spokes-person chosen in each group. The teacher wrote it on a sheet divided into two columns: one for the favourable opinions and one for the others. If the students' opinions were not clear enough she could rephrase it but with the agreement of the authors. Clearly, it would have been difficult for the teacher to take upon herself this last responsibility and to have acted as only the "memory of the class". But as we have explained it, this is unavoidable considering the students' age. Otherwise, more often than not, students playing "the teacher role" might enter a pointless debate on the quality of the writing. Only then did the debate upon the validity of the arguments begin.

We knew that, even more than in the preceding problem, students had at hand numerous different possible solutions for this problem. There is also a practical method to check the solution: to extend the lines over another sheet. But, considering the imprecision of this method, and some previous experiments, we expected it to appear inadequate.

\subsubsection{TRansmission of the SCEnARio of the Situation to the Teacher}

The aim of this second experiment was to examine the possibility of a faithful description of the scenario to a teacher who was not member of the research team. That is why we explained the scenario with so many details and why we will now carefully explain how we presented it to this teacher.

A priori, we thought that some difficulties would appear for the assimilation of the scenario by a teacher.

- Difficulties related to the class management which is not her typical situation.

- Difficulties due to the fact that she might be led to make decisions during the debate phase, which cannot completely be foreseen by the scenario.

Very likely, these decisions would not be taken randomly but according to teacher's ideas about the best conditions for the satisfactory functioning of the session. These ideas 
depend not only on the presentation we did but also on her personal ideas about the teacher's role, the nature of mathematics and the learning process of the children.

- Difficulties due to the plans of the researcher which are not quite the same as those of the teacher: The implementation of the didactical sequence is an experiment aiming at testing an hypothesis about students and proof. But quite normally, the aim of the teacher is that her students learn something. It is not obvious that these two aims are compatible.

To minimize these difficulties, as we have mentioned earlier, we organized three meetings with the teachers. These meetings had two aims:

- To show the teacher that there is some interest for her, and for her students to participate in this research. Here, we think that the interest is chiefly the implementation of a style of management of the class which can help her to know new practices and to become aware of the choices she usually makes in her class and of their motivations.

- To check that teachers entirely agreed with all the details of the scenario and understood the aim of the research regarding the place of proof in the teaching of mathematics. We even allowed the possibility of changing certain parts of the scenario rather than taking the risk of an experiment in which the teacher would not be at ease.

The three meetings had the following content:

- First meeting: Presentation of the general setting of the research and of the particular aim of the experiments in their classes.

- Second meeting: Viewing a video tape showing a class session with the same management of a research period and of a debate period. During this viewing we insisted upon the necessity for them to point out every management event which in their opinion would be impossible in their classes. It appeared that they did not foresee difficulties for the research period but that they clearly saw difficulties for the debate period: These included difficulties for them to respect the meaning of the arguments of the children, difficulty for students to listen with enough attention to the interventions of the others.

- Third meeting: It was devoted to a very detailed critique of the scenario. Each detail was discussed and negotiated: We emphasized the fact that it was better to change something in the scenario rather than to have a teacher poorly applying a scenario she did not entirely agree with. 


\subsubsection{The SCEnARIO AND its IMPLementation: Four MeANingful GaPS}

\subsubsection{LOOKING BACK TO THE TEACHER'S DECISIONS.}

At the end of the research period good and false solutions were proposed by students, which fitted the designed scenario. But differences appeared during the debate period between the intended scenario and its implementation and these differences were clear gaps. The importance of these gaps lies in the fact that they contributed to a limitation of the devolution of the problem to students. In the following we will illustrate and analyse each of the four major gaps identified (Mante, 1987, pp. 92-97).

\subsubsection{FIRST GAP: THE TEACHER ASKS QUESTIONS WHICH INDUCE ANSWERS.}

One of the student groups did not agree with a poster because, "the proposed method has not been proved". Then, in order to set the debate going the teacher asked: "Do all of you agree? It's not proved..."

Listening again to her words, the teacher recognizes that her question induces an answer. But she was not aware of that, as the following dialogue illustrates:

Teacher: "Time plays a role. I saw that there were no proofs. Then I entered the debate. I thought that it was clear to them that there were no proofs".

Observer: "You thought that students would agree and that as a consequence the debate would be more interesting..."

Teacher: "Right".

It is as if for each argument the teacher judged the related debate a priori. We find here again the effect of her feeling of her epistemological responsibility. Insofar as she thought the debate to be of no interest, she tried to shorten the time spent by asking questions inducing the answers she expected. This point is clearly made during the interview:

Teacher: "If we discuss all the arguments for the first poster: Do we have to prove or not... we will stay all the time on the same one, then no time will be left for the others. Therefore, instead of doing too much on the first poster, it's better to share the time among them."

So, we see that time is an essential factor which contributes to the determination of the teacher's decision. 


\subsubsection{SeCOND GAP: The TEACHER Does NOt TRANSCRIBE SOME STUdENTS'}

STATEMENTS.

This fact has been observed three times during the debate. Listening again to the record, the teacher is surprised:

Teacher: "Why have I done that? Not to transcribe that argument? Why have I avoided that? Question... must we take all arguments, even if they have already been rejected?" [...] "It's true, I classify the arguments. For example, the 'precise drawing' argument is not a real argument for me. It's not that important." Observer: "From your point of view?"

Teacher: "Yes indeed, but isn't it what we usually do in class?"

Her astonishment is an indication of her lack of awareness about this decision. From this interview we have an idea about the process which leads the teacher to decisions: For each student's argument she estimates the quality of the debate which will follow with respect to the target she is considering. This target depends on her own understanding of the scenario.

\subsubsection{THIRD GAP: THE TEACHER INTERVENES DIRECTLY ON THE DEBATE CONTENT.}

Among the arguments, one is made by a group which rejects a poster because "its authors have written that two straight fines (WM) and (WI) are equal".

Following this argument, the teacher entered the debate: "What worries me... I would like you to... Is the mistake $W M=W I$ that important?" She tried then to obtain a correction from the students:

Teacher: "It means that if two straight lines are confounded, then they are..."

Students: "Same distance..."

Students: "Equidistant..."

Teacher: "If you have say, it means something precise."

Student A: "They have a common point."

Student B: "Common point..."

Teacher: "No... If they are straight lines, they have no length, but it is still possible to draw a conclusion..."

Student B: "I don't know, please help us. What must we conclude?"

The teacher's comments during the interview enlighten this point:

Teacher: "I didn't expect that! We have worked so much on this aspect, to write that on a poster..."

Observer: "I think that you have had to make a strong effort to transcribe that." 
Teacher: "Yes, terrible... What's more, I have added a question mark." (Actually, after having written this argument she had added a question mark at its end) [...] "Yes, to tell that straight lines can be equal! And I have transcribed that. But it was the experiment..."

Here the experiment contradicts the teacher's beliefs about her role: She must not write false statements on the blackboard. This belief is shared by a number of teachers. Here again we see the effect of the teacher's epistemological responsibility. According to the teacher, the situation is not acceptable. She then tried to obtain from students the answer she wanted:

Teacher: "Well, I didn't think that I was so authoritative."

Observer: "You didn't remember this fact?"

Teacher: "Yes I did. But not that strongly. Here we can see that I push heavily..." Observer: "So, how do you explain that?"

Teacher: "I think that's basic knowledge. From the beginning of the school-year, that's something they know. So, to propose that as an argument... I must not... But such an argument is nothing but lesson content, as it were. Something they know well."

\subsubsection{FOURTH GAP: THE TEACHER REINFORCES SOME STUDENT'S WAYS OF}

PROVING.

When the time arrived for giving the arguments, one group specified that they did not agree with the method proposed by a poster because, "it works only if $M$ is on the bisector of the angle between the two lines $D$ and $D^{\prime}$." During the following debate, another group opposed this argument. Then the teacher proposed: "Now, you make a drawing in each group." After that, she asked a group who had finished its drawing to show it to the class. She concluded: "It works! But if $M$ is on the bisector!" Later in the debate, she urged students: "Look at your drawing and come to an agreement!".

So, the teacher reinforced a student's way of proving, the use of a drawing, that she would have refused in other circumstances. She did not suggest any other means than the use of the definition of the bisector... This will have a considerable influence on the continuation of the debate: The children will always remain at the level of using the drawings as a way of proving.

Later on, the teacher made a remark suggesting the limits of the use of drawing: "The width of a line, is it of no importance?" This last intervention obviously intended to provoke a debate about the reliability of drawings, but it failed since previous positive reinforcements of students' use of drawing were too strong. 
This teacher's intervention seems directly linked to her usual practice in geometry as we can see in the following extract of the interview:

Observer: "In your opinion, is a drawing a proof?."

Teacher (smiling): "Then, proof, verification, yes... We remain at the level of drawing for proving."

Observer: "But in your usual management of the class, if students make a drawing and tell you: Here is a proof. Do you agree?"

Teacher (laughing): "No, I don't."

Observer: "And why in this case did you impose the drawing as a possible way of proving?"

Then the teacher agreed with the fact that at this moment of the debate she was accepting drawings as possible proofs. But, later on:

Teacher: "When there are no counterexamples, it works."

Observer: "If it works on all the drawings, does it mean that the result is true?" Teacher: "Yes, it is. If there are no counterexamples."

Observer: "Do you accept that when it comes from students in a usual classroom?"

Teacher: "No, I don't."

Observer: "If you are working on a problem of this kind, and if the construction works for 5 to 6 drawings, do you conclude that, for you, it works? I am not speaking at a mathematical level, but for you... will you be convinced?"

Teacher: "If it works for 3 or 4 drawings, yes. Finally, I introduce my own conception of proof in this situation. But naturally, mathematically, a drawing allows us to see, not to prove."

So, the usual practice of this teacher, in geometry, appears here: In a geometrical problem, she usually confirms the truth of a solution by several drawings, and only then does she produce a mathematical proof if the need arises. In her classroom, she argues against students using drawings as a means to prove something. But, in some way, it is against her own practice. Here, her practice comes back to the fore insofar as she sees the situation as a break in her everyday way of managing her classroom. ${ }^{10}$

\subsubsection{CONCLUSION.}

We saw in this study that during the debate period, the teacher made several decisions opposite to the planned scenario. There were many limits to the devolution of the

10 This discussion with the teacher appears to us very important since it helps her to become aware of some aspects of her practice, and its influence on her decisions for the class management. It also leads her to clarify some elements of her personal relation to mathemat- ics that she did not realize before. It reveals a practice and perhaps an implicit theory (Cooney, 1988). 
situation. We also saw that the rationale of some of these decisions was not conscious for the teacher.

Looking for the origin of these decisions, we met again problems of time management and epistemological responsibility: Here epistemological responsibility appears in action. It is evidenced by the fact that the teacher eliminated some arguments and that she interpreted this later by a judgement on the interest for the debate that, in her opinion, these arguments could have produced. She also takes into account the fact that time is limited and must not be wasted in uninteresting debates. These two constraints explain for instance the elimination by the teacher of the arguments which would be, in her opinion, widely rejected by the children.

But moreover we saw two elements in the behaviour of the teacher which neither depend on time management nor epistemological responsibility:

- Teacher's personal relationship to mathematics: It appears here when the teacher used her usual procedure to gain certainty in the solution of a geometrical problem.

- Teachers' ideas about teaching and learning mathematics: Among other things, she thinks that she must not write false statements on the blackboard. This is probably linked to her ideas about learning and treatment of errors. Moreover, these ideas about learning are necessary to produce a priori judgements about the interest of children in some arguments: The decisions required by epistemological responsibility de- pend both on the situation and on the teacher's beliefs.

We recognize here some phenomena already underscored by several authors: The teacher's beliefs about mathematics, their teaching and learning, influence their teaching practice (Cooney, 1988; Ernest, 1988), and some authors even spoke of "personal theory of mathematics education" (Siemon, 1988). But we also saw that these personal beliefs could become constraints as well as epistemological responsibility and time management.

The fact that during the meeting with the teacher prior to the experiment, the questions which appear to be fundamental after the session did not arise, emphasizes the complexity of the relation between consciously held ideas and practice for the same teacher (Thompson, 1984) and the necessity of class observation. This points out that there are always implicit theories (Cooney, 1988) which appear through the actual management of the class. 
Finally, the modifications of the scenario of the researcher induced by the teacher who implements it, even if she previously entirely agreed with its content, are of interest to both researchers and teachers. For the first, it is a way to study teacher's beliefs. For the second, it is an opportunity to become conscious of their conceptions or at least of their patterns of action.

These observations give added significance to the collaboration between researchers and teachers.

\section{GENERAL CONCLUSIONS. PROBLEM OF REPRODUCIBILITY}

\subsection{Individual Stories Versus Class Stories}

Let us now come back to our initial question: What kind of phenomena can we expect to reproduce when the same class situation is implemented by two different teachers in two different classes? The answer is not that simple, but clearly the first thing to elucidate is what is interesting for research on learning of mathematics in an institutionalised system. Artigue (1986) points out that generally, in the French literature about didactique des mathématiques, the expected result is a dynamic reproducibility, that is to say, the reproduction of the same "story" of the class. And what is even more likely is the individual reproduction of the same learning story for each student in the class, or at least of a small number of different stories.

Artigue's conclusions are that this aim can be reached only by teacher's interventions and, especially in a problem-solving session, by teacher's interventions intended to make the spreading of ideas easier. She also emphasizes the danger for the teacher of obtaining a sort of global reproduction of the same "story of the class", using means which might change completely the meaning students could give to the situation. There is an opposition between this kind of forced global reproduction and the reproduction of individual learning stories. (This is the phenomenon of obsolescence, Brousseau 1986a).

\subsection{Preserving Meaning Behind Facts}

Now, we would like to show precisely what we wanted to reproduce in the situations we organized, before looking at the possible appearance in our cases of the dangers pointed out by Artigue: 
- During the research period, we thought it necessary that all students worked on the same problem, and that enough different solutions could appear in a reasonable time. This depends on the choice of problem prior to the experiment. If the problem is well chosen, then there is less chance that the teacher feels pressed to intervene during the research time.

- During the debate period, students are expected to engage individually in the debate. It is then necessary for them to understand the differences between the various solutions and to be prepared for discussion. But more precisely, it is expected they will produce arguments which are the focus of the expected learning. For instance, in the first problem about the truncated triangle, some debates were expected on the domain of validity of solutions leading to an isometric copy of the triangle. Roughly speaking, two positions could be held by students: Those who saw this question and those who did not. But the number of students in each position, the kind of isometry involved (symmetry, translation, or mere "reproduction") is not essential to us.

It is possible to distinguish, from the point of view of the teacher, two kinds of events: Those she can easily observe during the session and those she cannot easily observe. For example, the last category includes personal involvement of students, their awareness of contradictions, their evaluation of the correctness of arguments and so on. We can briefly state that the process of learning is not directly observable. Moreover, even if the situation is optimized to obtain specific individual behaviours, it favours but cannot determine them (Balacheff, 1987).

The behaviours that the teacher can observe constitute the global story of the class: In our case, for example, they consist essentially of the public productions, written or oral, of the students during the debate phase. If the expected learning behaviours occur, then this global story occurs, but unfortunately, the converse is obviously false. The danger then could be that, if the teacher thinks that the desired outcome does not occur, she might force its appearance. Here, we meet again the difficulty pointed out by Artigue and Brousseau: The fundamental aim of the situation, that is to say, the personal involvement of children, is forgotten.

We see that the description of the situation is linked to the kind of reproducibility we intend to obtain. We must describe the kind of phenomena we want to provoke and observe, but also the conditions for their appearance. In our case, it implies a careful specification of the teacher's role. On the contrary, if we try only to obtain the reproduction of mere observable facts, this could be easily performed. 


\subsection{ObSTACLES TO REPRODUCTION}

As a conclusion we will list and briefly comment on the origins of the obstacles to reproduction we met in our experiments:

- $\quad$ Short term management:

The most obvious obstacle is the fact that the expected effects must occur in a time compatible with the normal functioning of schools. For instance, it must not exceed two or three sessions in our experiments, so as the time moves on, the teacher becomes more and more inciting.

- $\quad$ Long term management:

We saw in the case of the second problem a conflict between the management of the session and the fact that at this time of the school-year, the teacher assumed a certain knowledge base to be held by students. Here she feels forced to intervene. This is an example of the possible contradiction between the aims of the researcher and those of the teacher: The free expression of the questions by the students interferes with the normal collective progression of knowledge in the class. This kind of problem has been studied by Chevallard (1985) under the name of "temps didactique". This phenomenon is also due to the fact that our experiments appear as an "extra" in the normal course of the class which they must not disturb.

- Teacher's epistemological responsibility:

That is to say, the necessity of obtaining a certain kind of behaviour supposed to evidence a certain kind of learning.

- Teacher's personal relationships to mathematics:

It becomes an obstacle when the teacher experiences a situation whose conception is in fact contradictory to her own epistemology. We also saw that our precautions consisting of carefully presenting the situation, and the theoretical ideas behind it, before the class session, to the teacher were not enough to avoid difficulties. There is a well-known general origin to this difficulty: Explicit conceptions can be different from those effectively engaged in problem solving. In our case, in the particular problem of class management, we can also see the emergence of a contradiction between the teacher's practice related to geometric problem solving, and the standard ideas she wants to communicate to students about proof in geometry. It is unlikely that such a contradiction could appear during the meeting prior to the experiment.

- Control by the teacher of the actual effects of her interventions of her "micro-decisions": 
It is a very difficult problem which raises the question of the possibility for the teacher to anticipate the behaviour of her students at two levels at least: cognitive and behavioural.

- At the behavioural level, we saw that interventions aiming to encourage the students can be understood in certain situations as approving a particular solution.

- At the cognitive level, we saw the teacher eliminating some arguments with respect to the quality of the debate they could produce, but in fact it is difficult for her to estimate that "quality" since generally she did not share the students' ideas (Grenier, 1988).

To satisfy the two basic constraints of time and teacher's epistemological responsibility, we must document very precisely all the students' solutions possible to appear in a given problem-situation, and to envisage the means to cope with false ones within the context of that situation. Here is a classical problématique of didactical research which is usually called "a priori analysis" (Brousseau, 1986a). It is the only way to reduce the teacher's uncertainty and to escape ad hoe didactical treatment. But, more than that, we must be able to give a precise evaluation of the time needed for a didactical process, considering it as a variable about which the teacher needs reliable information and perhaps the means to act upon it. It is one of the essential issues of research in mathematics education regarding its responsibility to teaching practice.

Finally, we want to point out that we can put together the obstacles to reproducibility due to the teacher's management in three categories:

- Constraints, such as time or epistemological responsibility;

- Personal ideas of the teacher, such as ideas about proof in geometry, but also about the management of the class;

- Problems of control of the actual effects of micro-decisions of the teacher.

The two first categories are well known. They are related to the idea that the teacher has less freedom in her class, even for her pedagogical choices. This can be found for instance in Shavelson and Stern (1981), Siemon (1988) and Suffolk (1988). These problems, and especially the problem of time management, have been widely studied by Chevallard (1985). On the other hand, the idea that the behaviour of the teacher in her class is widely influenced by her personal ideas about learning and teaching mathematics, even if this influence is not simple, has been often emphasized (Thompson, 1984). Quite obviously, these two points of view are partially contradictory: The second emphasizes the freedom of the teacher while the first insists on the limits of this freedom. Therefore, the interaction between the two points of view appears to be of central interest. It is for example considered in Cooney (1988). 
It may seem usual to study the problem of actual effects of teachers' decisions on students' learning, probably because the effects of these

decisions are generally seen only in terms of observable behaviours (Shavelson and Stern, 1981). It becomes a problem when we try to trace meanings behind facts.

\section{REFERENCES}

Arsac, G., Germain, G., and Mante, M. (1988) Problème ouvert et situation problème, IREM de Lyon, publication $n^{\circ} 64$.

Artigue, M. (1986) Modélisation et reproductibilité en didactique des mathématiques, Recherches en didactique des mathématiques 7(1), 5-62.

Balacheff, N. (1987) Processus de preuves et situations de validation, Educational Studies in Mathematics 18(2), 147-176.

Balacheff, N. (1988) Étude des processus de preuve en mathématique chez des élèves du premier cycle de renseignement secondaire, Thèse de doctorat d'état és-sciences. Université Joseph Fourier, Grenoble.

Balacheff, N. (1990) Towards a problématique for research on mathematics teaching', Journal for Research in Mathematics Education 21(4), 258-272.

Balacheff, N. (1991) Benefits and limits of social interaction: The case of teaching mathematical proof. In: Bishop, A., Mellin-Olsen, S., and Van Dormolen, J. (eds.), Mathematical Knowledge: its Growth through Teaching, Kluwer, Dordrecht (in press).

Brousseau, G. (1975) Étude de l'influence des conditions de validation sur l'apprentissage d'un algorithme. IREM-Université de Bordeaux 1, Bordeaux.

Brousseau, G. (1981) Problèmes de didactique des décimaux. Recherches en didactique des mathématiques 2(I), 37-127.

Brousseau, G. (1986a) Fondements et méthodes de la didactique des mathématiques, Recherches en didactique des mathématiques 7(2), 33-115.

Brousseau, G. (1986b) Forschungstendenzen der Mathematikdidaktik in Frankreich. Journal für Mathematik didaktik 7(2/3), 95-119.

Brousseau, G. (1989) Le contrat didactique : Le milieu. Recherches en didactique des mathématiques 9(3), 309-336.

Chazan, D. (1989) Ways of Knowing: High School Students' Conceptions of Mathematical Proof. Unpublished Doctoral Dissertation, Harvard Graduate School of Education, Cambridge, MA.

Chevallard, Y. (1985) La transposition didactique. La Pens6e Sauvage, Grenoble.

Cooney, J. (1988) A beginning teacher's view of problem solving. Journal for Research in Mathematical Education 16(5), pp. 324-336. 
Ernest, P. (1988) The impact of beliefs on the teaching of mathematics. Paper presented at the Sixth International Congress on Mathematical Education, Budapest, Hungary (unpublished).

Grenier, D. (1988) Construction et étude du fonctionnement d'un processus d'enseignement sur la symétrie orthogonale en sixième. Thèse, Université J. Fourier, Grenoble.

Legrand, M. (1988,) Genèse et étude sommaire d'une situation co-didactique: Le débat scientifique en situation d'enseignement. In: C. Laborde (ed.) Actes du premier colloque franco-allemand de didactique des mathématiques et de l'informatique. La Pensée Sauvage, Grenoble, pp. 53-66.

Lampert, M. (1988) The teacher's role in reinventing the meaning of mathematical knowing in the classroom. In: M. Behr and C. Lacampagne (eds.) Proceedings of the Tenth Annual Meeting of the North American Chapter of the International Group for the Psychology of Mathematics Education, pp. 433-480.

Mante, M.: 1987, Argumentation et preuve au collège, Mémoire de DEA de didactique des disciplines scientifiques, Universit6 Claude Bernard, Lyon.

Margolinas, C. (1989) Le point de rue de la validation: essai de synthèse et d'analyse en didactique des mathématiques. Thèse, Université Joseph Fourier, Grenoble.

Schoenfeld, A. H. (1988) When good teaching leads to bad results: The disaster of well taught mathematics courses. Educational Psychologist 23(2).

Shavelson, R. J. and Stern, P. (1981) Research on teacher's pedagogical thoughts, judgments, decisions and behavior. Review of Educational Research 51(4), 455-498.

Siemon, D. E. (1988) How autonomous is the teacher of mathematics? Paper presented at the Sixth International Congress on Mathematical Education, Budapest, Hungary (unpublished).

Suffolk, J. (1988) The role of the mathematics teacher in developing countries. Paper presented at the Sixth International Congress on Mathematical Education, Budapest, Hungary (unpublished).

Thompson, A. G. (1984) The relationship of teacher's conceptions of mathematics and mathematical teaching to instructional practice. Educational Studies in Mathematics $15,105-127$. 